\title{
Downregulation of organic cation transporter 1 (SLC22A1) is associated with tumor progression and reduced patient survival in human cholangiocellular carcinoma
}

\author{
ANJA LAUTEM $^{2 *}$, MICHAEL HEISE $^{2 *}$, ANDREAS GRÄSEL $^{1}$, MARIA HOPPE-LOTICHIUS $^{2}$, NINA WEILER $^{2}$, \\ DANIEL FOLTYS ${ }^{2}$, JOHANNA KNAPSTEIN ${ }^{1}$, JÖRN M. SCHATTENBERG ${ }^{1}$, ARNO SCHAD ${ }^{4}$, \\ ANCA ZIMMERMANN ${ }^{1}$, GERD OTTO ${ }^{2}$, HAUKE LANG ${ }^{3}$, PETER R. GALLE ${ }^{1}$, \\ MARCUS SCHUCHMANN $^{1}$ and TIM ZIMMERMANN ${ }^{1}$ \\ ${ }^{1}$ First Department of Internal Medicine, Departments of ${ }^{2}$ Hepatobiliary and Transplantation Surgery, and \\ ${ }^{3}$ General and Abdominal Surgery, ${ }^{4}$ Institute of Pathology, Johannes Gutenberg University Mainz, Mainz, Germany
}

Received November 20, 2012; Accepted January 11, 2013

DOI: $10.3892 /$ ijo.2013.1840

\begin{abstract}
Cholangiocellular carcinoma (CCA) is a primary hepatic malignancy derived from cholangiocytes. The prognosis for CCA patients is very poor and conventional chemotherapy has been proven ineffective in improving long-term patient survival rates. Organic cation transporters (OCTs) mediate the transport of a broad spectrum of endogenous substrates and the detoxification of xenobiotics. Moreover, OCTs are considered responsible for the responsiveness towards platinum-based chemotherapies. Currently, there are no data available regarding the role of OCTs in CCA. Therefore, the aim of this study was to investigate the expression of OCT1 and OCT3 in CCA and the corresponding non-neoplastic tumor-surrounding tissue (TST). OCT1 (SLC22Al) and OCT3 (SLC22A3) mRNA expression was measured in primary human CCA by real-time PCR $(n=27)$. Protein expression was determined by western blot analysis and immunohistochemistry. Data were correlated with the clinicopathological parameters of CCA. Real-time PCR demonstrated a downregulation of the expression of SLC22A1 and $S L C 22 A 3$ in CCA, compared to that in TST $(\mathrm{p}<0.001)$. A low SLC22Al expression was associated with a worse patient survival $(\mathrm{p}<0.05)$. The downregulation of $S L C 22 \mathrm{Al}$ was significantly associated with advanced CCA stages, since tumors with a low $S L C 22 A 1$ mRNA expression presented with larger tumor diameters $(\mathrm{p}=0.02)$. There were no significant differences in tumor characteristics or patient survival in relation to the level of $S L C 22 A 3$ expression. Western blot analysis
\end{abstract}

Correspondence to: Dr Tim Zimmermann, First Department of Internal Medicine, Johannes Gutenberg University Mainz, Langenbeckstr. 1, D-55131 Mainz, Germany

E-mail: tim.zimmermann@unimedizin-mainz.de

${ }^{*}$ Contributed equally

Key words: organic cation transporters 1 and 3, SLC22A1, SLC22A3, cholangiocellular carcinoma and immunohistochemistry confirmed the downregulation of OCT1 and OCT3 protein levels in cancerous tissue compared to those in TST. In conclusion, the downregulation of OCT1 is associated with tumor progression and worse overall patient survival rates.

\section{Introduction}

Cholangiocellular carcinoma (CCA) is the second most common hepatobiliary malignancy after hepatocellular carcinoma (HCC). With a growing incidence (2-4/100,000 per year), it accounts for approximately $15 \%$ of liver cancer cases worldwide $(1,2)$. CCAs grow as highly malignant adenocarcinomas, arising from the epithelial cells of intrahepatic bile ducts. Based on their anatomical origin, CCAs are classified into peripheral intrahepatic cholangiocarcinomas, originating from interlobular bile ducts, extrahepatic hilar (Klatskin) tumors and distal tumors, arising from the main hepatic ducts or the bifurcation of the common hepatic duct.

The only curative therapy for CCA is surgical resection; however, due to its non-specific symptoms, the tumor is usually diagnosed in its advanced stages, by which time it is non-resectable. The prognosis and overall survival for CCA patients is very poor. Even in resectable tumors, 5-year survival rates are $<15 \%$, with a $30 \%$ tumor recurrence rate $(2,3)$. Chemotherapeutic options for CCA are rather limited and the median survival with palliative chemotherapy is very low (4.6-15.4 months) (4). Therefore, novel molecular markers that may help predict clinical outcome and therapeutic response are urgently required.

The 3 organic cation transporters, OCT1 (SLC22A1), OCT2 (SLC22A2) and OCT3 [synonym: extraneuronal monoamine transporter (EMT); SLC22A3], belong to the amphiphilic solute facilitator (ASF) family of integral transmembrane proteins. They mediate the interactions between cells and their environment and are involved in numerous metabolic processes and detoxification. OCTs bidirectionally transport a broad spectrum of endogenous substrates (e.g., catecholamines), toxins and anticancer drugs (5). OCTs are determinants of the 
cytotoxicity of platinum derivatives (6). Therefore, these transporters are of pharmaceutical interest.

In humans, OCT1 is mainly expressed in the liver and OCT2 in the kidney, whereas OCT3 is widely distributed in a number of tissues. Nevertheless, OCTs exhibit overlapping substrate specificities and tissue expression patterns. They functionally substitute each other, ensuring that important metabolic pathways are still conducted, even though one OCT may be defective or deficient $(7,8)$.

We recently demonstrated a significant downregulation of OCT1 and OCT3 in human HCCs (9). We reported that the downregulation of OCT1 mRNA in HCC is associated with advanced tumor stages and worse overall patient survival rates.

Thus far, there are no studies available on OCT expression in CCA. To our knowledge, our study is the first to address this issue by investigating the effect of OCT expression on patient survival and tumor characteristics in CCA. Expression levels were measured in tumorous and corresponding non-neoplastic tumor-surrounding tissue (TST). The expression patterns were correlated with clinicopathological parameters and outcomes.

\section{Materials and methods}

Patient tissue samples. CCA and corresponding TST samples were obtained from 27 patients undergoing tumor resection between 2006 and 2011 at the Department of Hepatobiliary and Transplantation Surgery of the Johannes Gutenberg University Mainz, Germany. All CCA samples analyzed were classified as intrahepatic cholangiocarcinoma. Extrahepatic hilar (Klatskin) tumors or distal tumors were not included in this study. All CCAs analyzed were classified as M0 (no distant metastasis) and N0 (no regional lymph node metastasis), according to the WHO TNM classification of liver tumors. The patients did not receive any chemotherapy prior to resection. Detailed patient and tumor characteristics are listed in Table I. Informed consent was obtained from each patient. The study was conducted in accordance with the ethical guidelines of the declaration of Helsinki and was approved by the local ethics committee. Liver tissues were immediately shock-frozen following resection and stored in liquid nitrogen prior to analysis. All CCAs were diagnosed or confirmed by histological examination.

RNA isolation, reverse transcription real-time $P C R$ ( $q R T-P C R)$. RNA was extracted from the tissue samples by the High Pure RNA Tissue kit (Roche Diagnostics, Mannheim, Germany). cDNA preparation from total RNA was performed with 500 ng RNA (20 $\mu 1$ total volume) using the iScript cDNA Synthesis kit (Bio-Rad, Munich, Germany). All kits mentioned above were used according to the manufacturer's recommendations. Quantitative analyses of OCT1 (SLC22Al) and OCT3 (SLC22A3) transcripts were performed by qRT-PCR. The QuantiTect SYBR-Green PCR kit (Qiagen, Hilden, Germany) and validated primers of a QuantiTect Primer assay with the primer sets, HS_SLC22A1_1_SG (OCT1; 120-bp fragment), HS_SLC22A3_1_SG (OCT3; 115-bp fragment) and HS_GAPDH_2_SG (GAPDH; 119-bp fragment) (Qiagen), were used according to the manufacturer's instructions. For the amplification, an initial denaturation at $95^{\circ} \mathrm{C}$ for $15 \mathrm{~min}$, followed by $15 \mathrm{sec}$ at $94^{\circ} \mathrm{C}, 30 \mathrm{sec}$ at $55^{\circ} \mathrm{C}$ and $30 \mathrm{sec}$ at $72^{\circ} \mathrm{C}$ for 40 cycles was used. Samples were run on a LightCycler ${ }^{\circledR}$
Table I. Patient and tumor characteristics.

Characteristics

Number of patients

$\mathrm{n}=27$

Median follow-up in days (range)

$461(111-1363)$

Median recurrence-free survival

$161(0-1110)$

in days (range)

Gender (male/female; $\mathrm{n}$ )

$16 / 11$

Median age in years (range)

$66.5(32.4-83.7)$

Nodules (1-3/multiple; $\mathrm{n})$

$19 / 8$

Tumor diameter $(<3 \mathrm{~cm} />3 \mathrm{~cm} ; \mathrm{n})$

Median tumor diameter in $\mathrm{cm}$ (range)

$7.5(1.3-19.5)$

T-classification (T1/T2/T3; n)

$7 / 12 / 8$

Grading (G1/G2/G3/Gx $\left.{ }^{\mathrm{a}} ; \mathrm{n}\right)$

$1 / 21 / 4 / 1$

$\mathrm{CEA}(\mathrm{ng} / \mathrm{ml})(>5 /<5 ; \mathrm{n})^{\mathrm{b}}$

$5 / 20$

CA $19-9(\mathrm{ng} / \mathrm{ml})(>37 /<37 ; \mathrm{n})^{\text {b }}$

$13 / 12$

${ }^{\mathrm{a}} \mathrm{Gx}$, grade could not be assessed. ${ }^{\mathrm{b}}$ The status of 2 cases was unknown. CEA, carcinoembryonic antigen; CA 19-9, carbohydrate antigen 19-9.

480 real-time PCR system (Roche Diagnostics). The relative expression levels of OCT1 (SLC22A1) and OCT 3 (SLC22A3) mRNA in CCA and TST were calculated by normalization to GAPDH gene expression using the LightCycler ${ }^{\circledR} 480$ Software v1.5.0. For examination of OCT1 (SLC22Al) and OCT3 (SLC22A3) mRNA regulation, the relative mRNA expression of tumor tissue (CCA) was correlated with the relative mRNA expression of the corresponding TST. The median expression of this ratio was used to define a cut-off value to subdivide the tumor tissues into significantly or moderately downregulated CCAs.

Western blot analysis. Total protein extracts were prepared in sample buffer ( $\mathrm{pH} 8.0$ ) containing $20 \mathrm{mM}$ Tris, $5 \mathrm{mM}$ EDTA, $0.5 \%$ Triton X-100 and cOmplete, Mini, EDTA-Free Protease Inhibitors (1:25; Roche Diagnostics). For western blot analyses, $60 \mu \mathrm{g}$ of protein were loaded onto a $12 \%$ SDS-PAGE gel. The gel was transferred onto a nitrocellulose membrane (Optitran BA-S85; Whatman) following separation. Mouse anti-human OCT1 monoclonal antibody (1:1,000; Novus Biologicals, Littleton, CO, USA), rabbit anti-human OCT3 (1:2,000; LifeSpan Biosciences, Seattle, WA, USA) or mouse anti-human GAPDH polyclonal antiserum (1:5,000; EnoGene Biotech, New York, NY, USA) were used as the primary antibodies. Horseradish peroxidase (HRP)-conjugated anti-mouse or anti-rabbit IgG (DakoCytomation, Hamburg, Germany) were used as the secondary antibodies at 1:10,000 dilution. Protein bands were visualized using Western Lightning ${ }^{\circledR}$ Plus-ECL Enhanced Chemiluminescence Substrate (PerkinElmer, Waltham, MA, USA).

Immunohistochemistry. Immunohistochemical staining was performed on formalin-fixed, paraffin-embedded $4-\mu \mathrm{M}$ tissue sections. Following deparaffinization and rehydration, the endogenous peroxidase activity was inhibited with $4 \%$ hydrogen peroxide in methanol. For antigen retrieval, tissue sections 

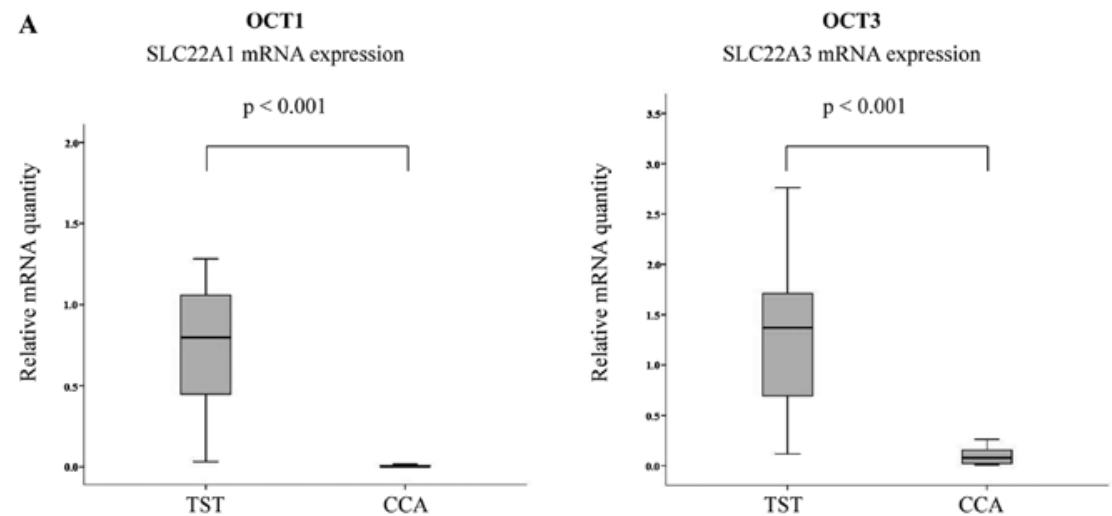

B
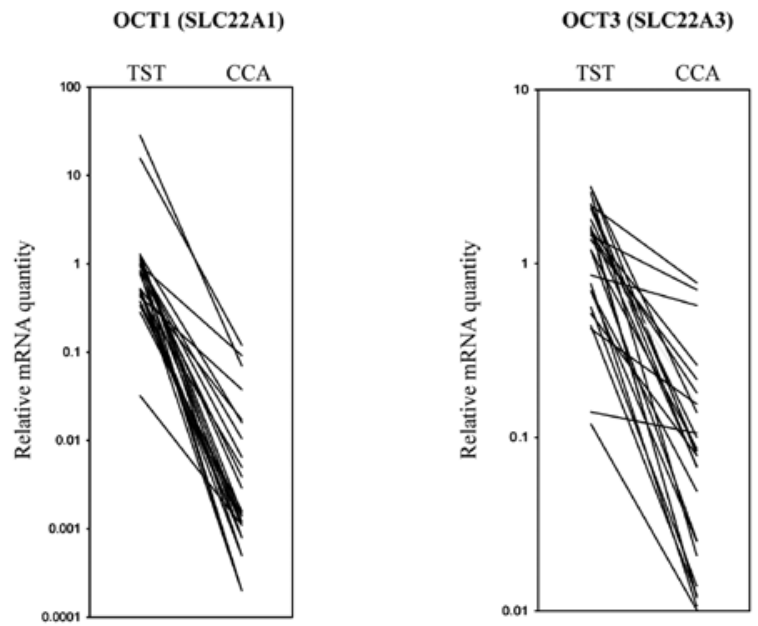

Figure 1. mRNA expression of OCT1 (SLC22A1) and OCT3 (SLC22A3) in cholangiocellular carcinoma (CCA) tissue and the corresponding non-neoplastic tumor surrounding tissue (TST). (A) Downregulation of OCT1 (SLC22A1) and OCT3 (SLC22A3) mRNA expression in CCA (n=27) and the corresponding non-neoplastic TST. (B) Individual OCT1 (SLC22A1) and OCT3 (SLC22A3) mRNA expression pattern in each patient (TST and CCA).

were treated for $20 \mathrm{~min}$ in a steamer in $10 \mathrm{mM}$ citrate buffer (pH 6.0). Cells were permeabilized with $2 \%$ saponin in PBS for $20 \mathrm{~min}$ at room temperature. For blocking of non-specific antibody binding, tissues were incubated for $30 \mathrm{~min}$ with protein blocking buffer (5\% normal serum, $0.2 \%$ Triton-X and 2\% BSA). The following primary antibodies were used for immunohistochemistry: mouse monoclonal anti-human OCT1 antibody (Novus Biologicals) and rabbit monoclonal anti-human OCT3 antibody (Epitomics, Burlingame, CA, USA) and incubated overnight at $4{ }^{\circ} \mathrm{C}$ in PBS (2\% saponin, 5\% BSA and 5\% normal serum). For the control sections, the specific primary antibody was omitted. The following day, sections were washed 3 times and incubated for 20 min with Pierce Peroxidase Suppressor (Thermo Fisher Scientific, Epsom, UK). After washing, the sections were incubated with a secondary biotinylated antirabbit or anti-mouse antibody (DakoCytomation), then treated with the avidin-biotin-peroxidase complex-based Vectastain Elite ABC kit (Vector Laboratories, Burlingame, CA, USA). Following incubation with HRP-conjugated streptavidin, tissues were dyed with diaminobenzidine (DAB) substrate (Sigma-Aldrich, St. Louis, MO, USA). Counterstaining was performed with Meyer's hemalaun solution and slides were mounted for examination under a light microscope.

Statisticalanalysis. Data management and all statistical analyses were performed with the SPSS program (IBM ${ }^{\circledR}$ SPSS $^{\circledast}$ v19.0).
For categorical variables, between-group differences were analyzed by the Chi-square or Fisher's exact test. For quantitative variables, data were expressed as median and range. If distribution was normal and sample sizes tested sufficient, the equality of variances was analyzed with the Levene's test and samples were compared using the paired t-test. If variables were not normally distributed or sample size was inadequate, we applied the Wilcoxon rank-sum non-parametric test. All tests were performed using a 5\% level of significance (two-sided). Overall survival rates were calculated using the Kaplan-Meier method and compared using the log-rank test.

\section{Results}

Expression of OCT1 (SLC22A1) and OCT3 (SLC22A3) mRNA in CCA . To analyze the role of OCT1 and OCT3 in malignant cholangiocarcinoma, we first investigated the mRNA expression of $S L C 22 A 1$ and $S L C 22 A 3$ in CCA tissue and corresponding non-neoplastic TST (n=27). qRT-PCR results demonstrated significant differences in the expression of $S L C 22 A 1 \mathrm{mRNA}$ between TST and CCA (Fig. 1A). SLC22A1 and SLC22A3 mRNA were highly expressed in TST and distinctly downregulated in cancerous tissues ( $\mathrm{p}<0.001$; Fig. 1A).

Individual expression patterns in CCA and the corresponding TST are presented in Fig. 1B. In CCA tissues, the median SLC22A1 mRNA expression was reduced by $99.7 \%$ 
A

Survival according to SLC22A1 mRNA expression

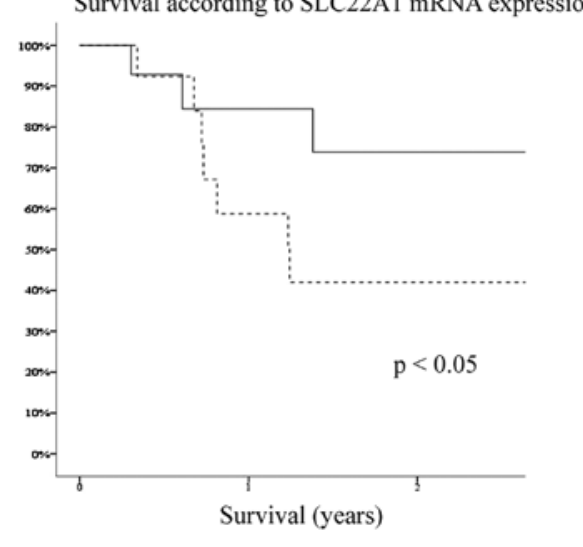

Tumor recurrence according

to SLC22A1 mRNA expression

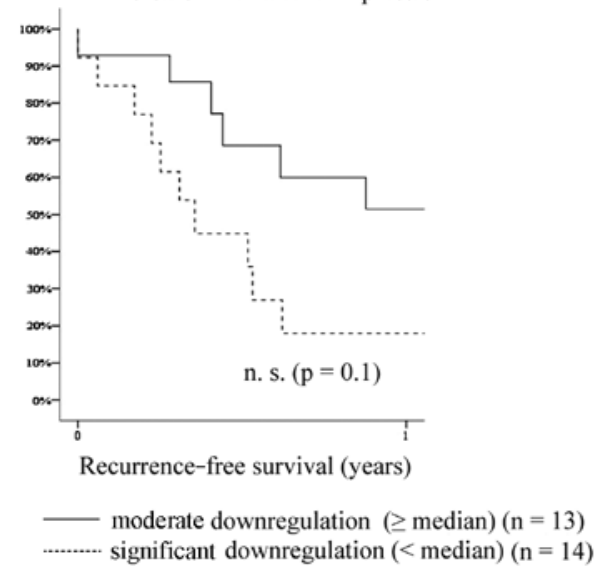

B

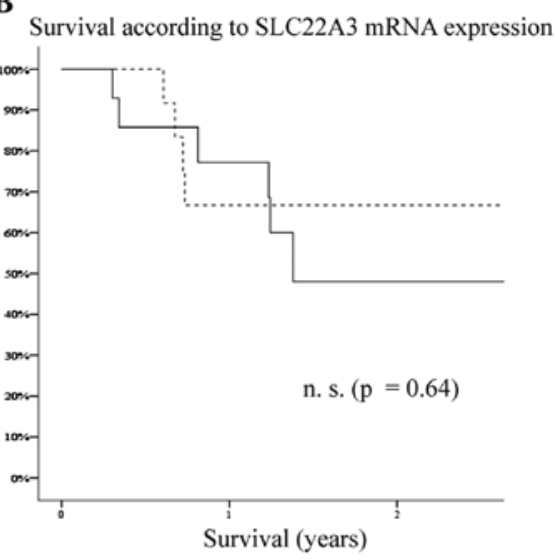

Tumor recurrence according to SLC22A3 mRNA expression

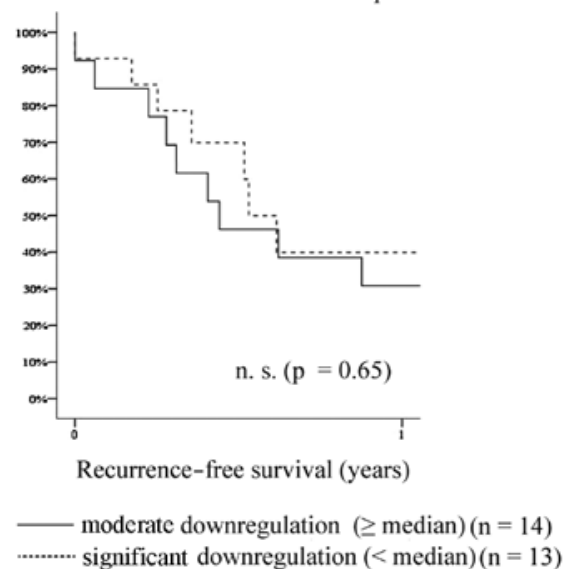

Figure 2. Survival and tumor recurrence of cholangiocellular carcinoma (CCA) patients according to the intratumoral (A) OCT1 (SLC22A1) or (B) OCT3 (SLC22A3) mRNA downregulation. The median downregulation of SLC22A1 and SLC22A3 mRNA expression in CCA tissue compared to the corresponding non-neoplastic tumor surrounding tissue (TST) (ratio of mRNA expression in CCA/mRNA expression in TST) was used as the cut-off value. CCA patients were subdivided into a moderately downregulated (CCA/TST expression level $\geq$ median) and a significantly downregulated group (CCA/TST expression level < median), according to the extent of SLC22A1 or SLC22A3 mRNA downregulation in CCA tissue compared to that in TST. n.s., non-significant.

compared to that in the corresponding TST (min, 90.5\%; max, 99.9\%). The median SLC22A3 mRNA expression of CCA tissues was also lower by $94.4 \%$ ( $\min , 24.5 \%$; $\max , 99.3 \%)$ than that in TST (Fig. 1A and B). The details of patient and tumor clinicopathological characteristics are summarized in Table I, according to WHO specifications.

Patient survival and tumor recurrence in patients with intratumoral OCT1 (SLC22A1) or OCT3 (SLC22A3) downregulation. According to the qRT-PCR results, we divided the patients into 2 groups: a significantly downregulated (CCA/TST expression level < median) and a moderately downregulated group (CCA/ TST expression level $\geq$ median). As regards the SLC22AI mRNA expression, overall patient survival was significantly reduced in patients with a significant downregulation of SLC22A1 mRNA expression $(\mathrm{p}<0.05)$ (Fig. 2A). The significant downregulation of $S L C 22 A 1$ did not markedly affect the risk of early tumor recurrence within the first year following resection $(\mathrm{p}=0.11)$ (Fig. $2 \mathrm{~A})$.

Although OCT3 (SLC22A3) mRNA expression was downregulated as well, the overall survival and tumor recurrence rates of CCA patients with a significant downregulation of SLC22A3 mRNA were not markedly different from those of patients with a moderate downregulation of SLC22A3 mRNA expression (overall survival, $\mathrm{p}=0.64$; tumor recurrence, $\mathrm{p}=0.65$ ) (Fig. 2B).

Patient and tumor characteristics in relation to OCT1 (SLC22A1) and OCT3 (SLC22A3) mRNA expression. Low $S L C 22 A 1$ mRNA expression levels were associated with advanced CCA stages, since CCAs with a low SLC22A1 mRNA expression presented with larger tumor diameters $(\mathrm{p}=0.02)$ (Table II). SLC22A1 mRNA expression did not correlate with other tumor characteristics (Table II). There was no significant difference in tumor characteristics in relation to $S L C 22 A 3$ mRNA expression (Table III).

Protein expression of OCT1 and OCT3 in human CCAs. To examine the protein expression levels of the transporters in CCA, we performed western blot analysis in CCA tissue and corresponding TST. Fig. 3A depicts the significant downregulation of OCT1 and OCT3 in CCA tissue compared to that in the corresponding TST of 4 patients. The downregulation of OCT1 and OCT3 proteins, as detected by western blot analysis, correlated well with the corresponding mRNA levels measured by qRT-PCR (Fig. 1A). 
Table II. Patient and tumor characteristics in relation to the intratumoral OCT1 (SLC22Al) mRNA expression.

\begin{tabular}{|c|c|c|c|}
\hline \multirow[b]{2}{*}{ Characteristics } & \multicolumn{2}{|c|}{ OCT1 $(S L C 22 A 1)$} & \multirow[b]{2}{*}{ p-value } \\
\hline & $\begin{array}{l}\text { Moderate downregulation } \\
\qquad(\geq \text { median })\end{array}$ & $\begin{array}{l}\text { Significant downregulation } \\
\qquad(<\text { median })\end{array}$ & \\
\hline Number of patients & 14 & 13 & \\
\hline Median follow-up in days (range) & $533(111-1363)$ & $451(125-1177)$ & 0.30 (n.s.) \\
\hline Median recurrence-free survival in days (range) & $273(0-1110)$ & $125(0-833)$ & 0.12 (n.s.) \\
\hline Male/female (n) & $8 / 6$ & $8 / 5$ & 1.00 (n.s.) \\
\hline Median age in years (range) & $64(32-84)$ & $69(44-82)$ & 0.43 (n.s.) \\
\hline 1-3 Nodules/multiple nodules (specimen) & $10 / 4$ & $9 / 4$ & 1.00 (n.s.) \\
\hline Tumor diameter $<3 \mathrm{~cm} / \geq 3 \mathrm{~cm}(\mathrm{n})$ & $3 / 11$ & $1 / 12$ & 0.60 (n.s.) \\
\hline Median tumor diameter in cm (range) & $4.8(1.3-12.0)$ & $12.8(1.7-19.5)$ & 0.02 \\
\hline T-classification (T1/T2/T3/T4) (n) & $3 / 8 / 2 / 1$ & $4 / 4 / 4 / 1$ & 0.55 (n.s.) \\
\hline Grading (G1/G2/G3/Gx $\left.{ }^{a}\right)(n)$ & $1 / 10 / 3 / 0$ & $0 / 11 / 1 / 1$ & 0.39 (n.s.) \\
\hline $\operatorname{CEA}(\mathrm{ng} / \mathrm{ml})>5 /<5(\mathrm{n})^{\mathrm{b}}$ & $3 / 10$ & $2 / 10$ & 1.00 (n.s.) \\
\hline CA $19-9(\mathrm{ng} / \mathrm{ml})>37 /<37(\mathrm{n})^{\mathrm{b}}$ & $7 / 6$ & $6 / 6$ & 1.00 (n.s.) \\
\hline $\begin{array}{l}S L C 22 A 3 \text { mRNA expression } \\
\text { ratio CCA/TST (range) }\end{array}$ & $\begin{array}{c}0.072 \\
(0.028-0.755)\end{array}$ & $\begin{array}{c}0.043 \\
(0.073-0.670)\end{array}$ & 0.24 (n.s.) \\
\hline
\end{tabular}

${ }^{\mathrm{a}} \mathrm{Gx}$, grade could not be assessed. ${ }^{\mathrm{b}}$ The status of 2 cases was unknown. CEA, carcinoembryonic antigen; CA 19-9, carbohydrate antigen 19-9; CCA, cholangiocellular carcinoma; TST, tumor-surrounding tissue; n.s., non-significant. Number in bold indicates statistical signficance.

Table III. Patient and tumor characteristics in relation to the intratumoral OCT3 (SLC22A3) mRNA expression.

\begin{tabular}{|c|c|c|c|}
\hline \multirow[b]{2}{*}{ Characteristics } & \multicolumn{2}{|c|}{ OCT3 (SLC22A3) } & \multirow[b]{2}{*}{ p-value } \\
\hline & $\begin{array}{l}\text { Moderate downregulation } \\
\qquad(\geq \text { median })\end{array}$ & $\begin{array}{l}\text { Significant downregulation } \\
\qquad(<\text { median })\end{array}$ & \\
\hline Number of patients & 13 & 14 & \\
\hline Median follow-up in days (range) & $823(161-1363)$ & $458(111-1357)$ & 0.22 (n.s.) \\
\hline Median recurrence-free survival in days (range) & $161(0-1110)$ & $165(0-833)$ & 0.87 (n.s.) \\
\hline Male/female (n) & $9 / 4$ & $7 / 7$ & 0.44 (n.s.) \\
\hline Median age in years (range) & $63(32-76)$ & $70(34-84)$ & 0.14 (n.s.) \\
\hline 1-3 Nodules / multiple nodules (specimen) & $8 / 5$ & $11 / 3$ & 0.42 (n.s.) \\
\hline Tumor diameter $<3 \mathrm{~cm} / \geq 3 \mathrm{~cm}(\mathrm{n})$ & $1 / 12$ & $3 / 11$ & 0.60 (n.s.) \\
\hline Median tumor diameter in $\mathrm{cm}$ (range) & $6.5(2.5-18.3)$ & $8.4(1.3-19.5)$ & 0.94 (n.s.) \\
\hline T-classification (T1/T2/T3/T4) (n) & $4 / 4 / 3 / 2$ & $3 / 8 / 3 / 0$ & 0.33 (n.s.) \\
\hline Grading (G1/G2/G3/Gx $\left.x^{a}\right)(n)$ & $0 / 10 / 3 / 0$ & $1 / 11 / 1 / 1$ & 0.39 (n.s.) \\
\hline $\operatorname{CEA}(\mathrm{ng} / \mathrm{ml})>5 /<5(\mathrm{n})^{\mathrm{b}}$ & $4 / 9$ & $1 / 11$ & 0.32 (n.s.) \\
\hline CA $19-9(\mathrm{ng} / \mathrm{ml})>37 /<37(\mathrm{n})^{\mathrm{b}}$ & $7 / 5$ & $6 / 7$ & 0.70 (n.s.) \\
\hline $\begin{array}{l}S L C 22 A 1 \text { mRNA expression } \\
\text { ratio CCA/TST (range) }\end{array}$ & $\begin{array}{c}0.004 \\
(0.001-0.095)\end{array}$ & $\begin{array}{c}0.002 \\
(0.0002-0.089)\end{array}$ & 0.26 (n.s.) \\
\hline
\end{tabular}

${ }^{\mathrm{a}} \mathrm{Gx}$, grade could not be assessed. ${ }^{\mathrm{b}}$ The status of 2 cases was unknown. CEA, carcinoembryonic antigen; CA 19-9, carbohydrate antigen 19-9; CCA, cholangiocellular carcinoma; TST, tumor-surrounding tissue; n.s., non-significant.

To identify the localization of OCT1 and OCT3 expression in tumor tissue, we subsequently assessed protein expression by immunohistochemistry (Fig. 3B and C). Fig. 3B shows the strong membranous OCT3 staining of bile duct epithelial cells in a normal liver portal field. Fig. 3C depicts OCT1 and OCT3 staining at the tumor border. In detail, we detected a 

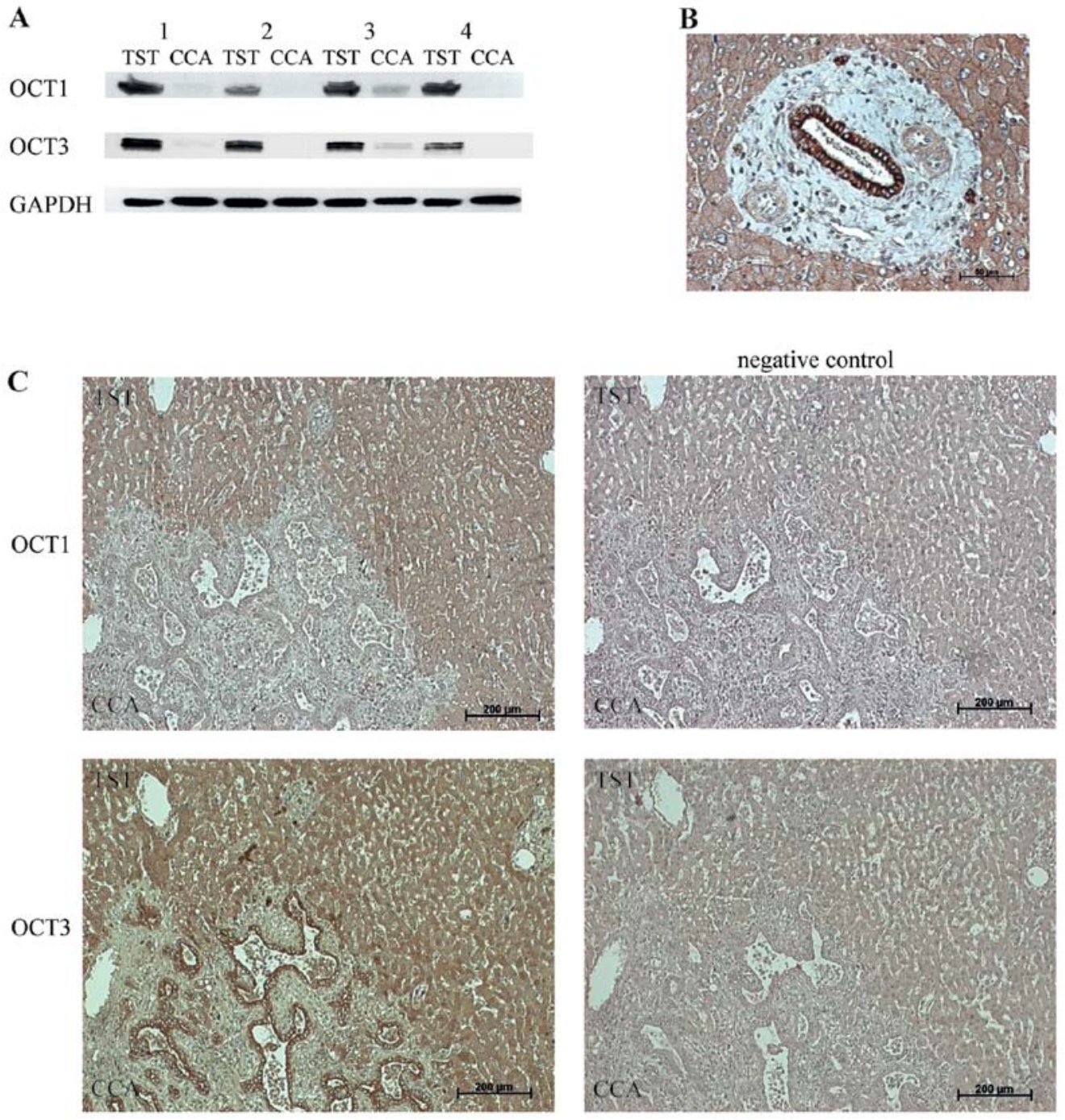

Figure 3. Western blot analysis and immunohistochemistry of OCT1 and OCT3 protein expression in cholangiocellular carcinoma (CCA) tissue and the corresponding non-neoplastic tumor-surrounding tissue (TST). (A) Western blot analysis of 4 patients (1-4) with CCA and the corresponding TST (OCT1: 61 kD; OCT3: $60 \mathrm{kD}$ ). (B) OCT3 expression in bile duct epithelial cells. OCT3 expression is exemplarily shown in bile duct epithelial cells in a normal liver portal field (TST) of a CCA patient. Bile duct epithelial cells exhibited a strong membranous staining of OCT3. (C) Analysis of OCT1 and OCT3 protein expression by immunohistochemistry. OCT1 and OCT3 protein expression at the tumor border of a CCA patient is demonstrated. OCT1 presents with a predominantly membranous staining of hepatocytes in non-neoplastic TST, whereas it is almost completely absent in tumor tissue. In TST, hepatocytes were also positively stained for OCT3. For the negative control, the specific antibody was omitted during the staining procedure.

predominantly membranous staining of OCT1 and OCT3 in TST hepatocytes. OCT1 staining was not detected in carcinoma cells (Fig. 3C). Positive staining of OCT3 was observed in the membrane of bile duct epithelial cells in carcinomatous (Fig. 3C) as well as normal liver tissue.

\section{Discussion}

OCTs have been extensively investigated in several types of tissue and tumor cell lines. However, data regarding their presence and role in human malignancies are limited (10-12). We recently demonstrated a significant downregulation of OCT1 and OCT3 in human HCCs and reported that the downregulation of OCT1 mRNA in HCC is associated with advanced tumor stage and poor patient survival (9). To date, there are no data available regarding OCT expression in human CCA. Therefore, to the best of our knowledge, this study is the first to analyze the expression profiles of the OCTs in human CCA with direct correlation to clinical and tumor-specific data.

The human CCA samples analyzed, revealed a significant downregulation of OCT1 (SLC22A1) and OCT3 (SLC22A3) expression in cancerous tissue compared to the corresponding non-neoplastic TST $(\mathrm{p}<0.001)$. Our results are the first to provide evidence that the downregulation of SLC22Al mRNA expression is associated with advanced tumor stage and worse overall patient survival (Table II and Fig. 2A). Median tumor diameters of the CCAs with a significant downregulation of SLC22A1 mRNA (CCA/TST expression level < median) were significantly larger than those of the CCAs with a moderate downregulation of SLC22A1 mRNA (CCA/TST expression level $\geq$ median) $(\mathrm{p}=0.02$, Table II). The OCT1 and OCT3 proteins were also downregulated in the cancerous tissues, as demonstrated by western blot analysis (Fig. 3A) and immunohistochemistry (Fig. 3C). Whether the intratumoral downregulation 
of the OCTs results in more aggressive cancer growth remains to be elucidated. The results from qRT-PCR and western blot analyses demonstrated a more significant downregulation of OCT1 (SLC22Al) mRNA and protein, in comparison to OCT3 (SLC22A3). This may be explained by the positive OCT3 staining of bile duct epithelial cells in CCA tissue and TST, which was distinctly demonstrated by immunohistochemistry (Fig. 3B and C). At present, we can only hypothesize that the expression of OCT3 in bile duct epithelial cells plays an important role in transporting physiological substrates to regulate bile flow or to protect the cells from bile toxicity.

Although OCTs are functionally influenced by several endogenous and exogenous substances, to date, data regarding the pathways and regulatory mechanisms of OCT expression in cancer are limited. The transporters are located on the chromosomal locus 6q26-27 in a conserved gene cluster and are influenced by genomic imprinting mechanisms involving the insulin-like growth factor 2 receptor (IGF2R) tumor suppressor gene $(13,14)$. This may contribute to the complex genetic and epigenetic regulations in the context of human malignancy. Recently, Schaeffeler et al (15) revealed that the DNA methylation of $S L C 22 A 1$ was associated with the downregulation of $S L C 22 A 1$ in HCC and suggested that the targeting of SLC22AI methylation by demethylating agents may provide a novel strategy for the treatment of HCC. Further studies are required to elucidate the mechanism involved in the downregulation of OCTs in CCA.

OCTs may play an important role in the therapy of malignant tumors, since they are considered responsible for the cytotoxicity of platin derivatives in colorectal cancer $(6,16,17)$. OCTs are major determinants of the anticancer activity of oxaliplatin and it has been suggested by Zhang et al that the expression of OCTs in tumors should be assessed as a marker for selecting specific platinum-based therapies in individual patients (6).

In general, bile duct tumors are known to be relatively unresponsive to conventional chemotherapy. Gemcitabine combined with platinum compounds (e.g., oxaliplatin) has been recommended as palliative chemotherapy in advanced biliary tract cancer $(18,19)$. The chemotherapeutic outcome and median survival times are still quite limited, with short life expectancies (not exceeding 15.4 months). In a recent phase 2 study, Gruenberger et al achieved improved response rates for CCA (63\%) with a combination therapy of GEMOX (gemcitabine and oxaliplatin) and cetuximab (monoclonal anti-EGFR antibody; EGFR kinase inhibitor) (3). Due to the limited number of patients included in our study and the short survival times of the CCA patients following resection, it was not possible to correlate OCT downregulation with the therapeutic response to platinum derivates. Further studies are warranted to evaluate the potential diagnostic and therapeutic consequences of OCT regulation in CCA.

Furthermore, it is unclear whether the transporters are functional in CCA tissue and corresponding non-neoplastic TST. To date, several genetic variations of SLC22A1 $(20,21)$ and $S L C 22 A 3$ (22-24) have been identified. There are no data available concerning the genetic variations of the OCT genes in CCA. Further investigation of non-functional or reduced-function polymorphisms of OCTs in CCA is required, since genetic polymorphisms of these genes may significantly influence the transport and action of drugs $(25,26)$. Furthermore, in colorectal cancer, a common mutation in the $S L C 22 A 3$ gene was identified and associated with the increased risk of distal colon cancer in an Asian population (27). Another single nucleotide polymorphism (SNP) in the $S L C 22 A 3$ gene has been shown to be associated with prostate cancer in Caucasian populations (28). Thus, $S L C 22 A 3$ is likely associated with multiple types of cancer.

In conclusion, this study demonstrates that OCTs are downregulated in CCA and, to our knowledge, we are the first to provide evidence that the downregulation of OCT1 is associated with a worse overall patient survival. Further studies are required to determine the role of OCTs in CCA development and treatment. The downregulation of OCT1 (SLC22A1) expression in CCA is associated with larger tumor diameters and a worse overall patient survival. These findings may prove to be significant for the treatment of CCA.

\section{Acknowledgements}

We would like to thank Larissa Herbel, First Department of Internal Medicine, University of Mainz and Ulrike Suessdorf, Department of Hepatobiliary and Transplantation Surgery, University of Mainz, for their excellent technical assistance with the patient samples. The present study was supported by an intramural fund of the University of Mainz (MAIFOR grant) to Tim Zimmermann.

\section{References}

1. Khan SA, Toledano MB and Taylor-Robinson SD: Epidemiology, risk factors, and pathogenesis of cholangiocarcinoma. HPB (Oxford) 10: 77-82, 2008.

2. Seol MA, Chu IS, Lee MJ, Yu GR, Cui XD, Cho BH, Ahn EK, Leem SH, Kim IH and Kim DG: Genome-wide expression patterns associated with oncogenesis and sarcomatous transdifferentation of cholangiocarcinoma. BMC Cancer 11: 78, 2011.

3. Gruenberger B, Schueller J, Heubrandtner U, Wrba F, Tamandl D, Kaczirek K, Roka R, Freimann-Pircher S and Gruenberger T: Cetuximab, gemcitabine, and oxaliplatin in patients with unresectable advanced or metastatic biliary tract cancer: a phase 2 study. Lancet Oncol 11: 1142-1148, 2010.

4. Xu L, Hausmann M, Dietmaier W, Kellermeier S, Pesch T, Stieber-Gunckel M, Lippert E, Klebl F and Rogler G: Expression of growth factor receptors and targeting of EGFR in cholangiocarcinoma cell lines. BMC Cancer 10: 302, 2010.

5. White DL, Radich J, Soverini S, Saunders VA, Frede AK, Dang P, Cilloni D, Lin P, Mongay L, Woodman R, Manley P, Slader C, Kim DW, Pane F, Martinelli G, Saglio G and Hughes TP: Chronic phase chronic myeloid leukemia patients with low OCT-1 activity randomized to high-dose imatinib achieve better responses and have lower failure rates than those randomized to standard-dose imatinib. Haematologica 97: 907-914, 2012.

6. Zhang S, Lovejoy KS, Shima JE, Lagpacan LL, Shu Y, Lapuk A, Chen Y, Komori T, Gray JW, Chen X, Lippard SJ and Giacomini KM: Organic cation transporters are determinants of oxaliplatin cytotoxicity. Cancer Res 66: 8847-8857, 2006.

7. Jonker JW, Wagenaar E, Van Eijl S and Schinkel AH: Deficiency in the organic cation transporters 1 and 2 (Oct1/Oct2 [Slc22a1/Slc22a2]) in mice abolishes renal secretion of organic cations. Mol Cell Biol 23: 7902-7908, 2003.

8. Zwart R, Verhaagh S, Buitelaar M, Popp-Snijders C and Barlow DP: Impaired activity of the extraneuronal monoamine transporter system known as uptake-2 in Orct3/Slc22a3-deficient mice. Mol Cell Biol 21: 4188-4196, 2001.

9. Heise M, Lautem A, Knapstein J, Schattenberg JM, Hoppe-Lotichius M, Foltys D, Weiler N, Zimmermann A, Schad A, Gründemann D, Otto G, Galle PR, Schuchmann M and Zimmermann T: Downregulation of organic cation transporters OCT1 (SLC22A1) and OCT3 (SLC22A3) in human hepatocellular carcinoma and their prognostic significance. BMC Cancer 12: 109, 2012. 
10. Chang Q, Chen J, Beezhold KJ, Castranova V, Shi X and Chen F: JNK1 activation predicts the prognostic outcome of the human hepatocellular carcinoma. Mol Cancer 8: 64, 2009.

11. Okabe H, Satoh S, Kato T, Kitahara O, Yanagawa R, Yamaoka Y, Tsunoda T, Furukawa Y and Nakamura Y: Genome-wide analysis of gene expression in human hepatocellular carcinomas using cDNA microarray: identification of genes involved in viral carcinogenesis and tumor progression. Cancer Res 61: 2129-2137, 2001.

12. Park T, Yi SG, Shin YK and Lee S: Combining multiple microarrays in the presence of controlling variables. Bioinformatics 22: 1682-1689, 2006.

13. Verhaagh S, Schweifer N, Barlow DP and Zwart R: Cloning of the mouse and human solute carrier 22a3 (Slc22a3/SLC22A3) identifies a conserved cluster of three organic cation transporters on mouse chromosome 17 and human 6q26-q27. Genomics 55: 209-218, 1999.

14. Zwart R, Sleutels F, Wutz A, Schinkel AH and Barlow DP Bidirectional action of the Igf2r imprint control element on upstream and downstream imprinted genes. Genes Dev 15: 2361-2366, 2001.

15. Schaeffeler E, Hellerbrand C, Nies AT, Winter S, Kruck S, Hofmann U, van der Kuip H, Zanger UM, Koepsell $\mathrm{H}$ and Schwab M: DNA methylation is associated with downregulation of the organic cation transporter OCT1 (SLC22A1) in human hepatocellular carcinoma. Genome Med 3: 82, 2011.

16. Kitada N, Takara K, Minegaki T, Itoh C, Tsujimoto M, Sakaeda T and Yokoyama T: Factors affecting sensitivity to antitumor platinum derivatives of human colorectal tumor cell lines. Cancer Chemother Pharmacol 62: 577-584, 2008.

17. Yokoo S, Masuda S, Yonezawa A, Terada T, Katsura T and Inui K: Significance of organic cation transporter 3 (SLC22A3) expression for the cytotoxic effect of oxaliplatin in colorectal cancer. Drug Metab Dispos 36: 2299-2306, 2008.

18. Eckel F and Schmid RM: Chemotherapy in advanced biliary tract carcinoma: a pooled analysis of clinical trials. Br J Cancer 96: 896-902, 2007

19. Valle J, Wasan H, Palmer DH, Cunningham D, Anthoney A, Maraveyas A, Madhusudan S, Iveson T, Hughes S, Pereira SP, Roughton $\mathrm{M}$ and Bridgewater J: Cisplatin plus gemcitabine versus gemcitabine for biliary tract cancer. N Engl J Med 362: 1273-1281, 2010.

20. Kerb R, Brinkmann U, Chatskaia N, Gorbunov D, Gorboulev V, Mornhinweg E, Keil A, Eichelbaum M and Koepsell H: Identification of genetic variations of the human organic cation transporter hOCT1 and their functional consequences. Pharmacogenetics 12: 591-595, 2002.
21. Sakata T, Anzai N, Shin HJ, Noshiro R, Hirata T, Yokoyama H, Kanai $\mathrm{Y}$ and Endou $\mathrm{H}$ : Novel single nucleotide polymorphisms of organic cation transporter 1 (SLC22A1) affecting transport functions. Biochem Biophys Res Commun 313: 789-793, 2004.

22. Chen L, Pawlikowski B, Schlessinger A, More SS, Stryke D, Johns SJ, Portman MA, Chen E, Ferrin TE, Sali A and Giacomini KM: Role of organic cation transporter 3 (SLC22A3) and its missense variants in the pharmacologic action of metformin. Pharmacogenet Genomics 20: 687-699, 2010.

23. Lazar A, Gründemann D, Berkels R, Taubert D, Zimmermann T and Schömig E: Genetic variability of the extraneuronal monoamine transporter EMT (SLC22A3). J Hum Genet 48: 226-230, 2003.

24. Sakata T, Anzai N, Kimura T, Miura D, Fukutomi T, Takeda M, Sakurai $\mathrm{H}$ and Endou $\mathrm{H}$ : Functional analysis of human organic cation transporter OCT3 (SLC22A3) polymorphisms. J Pharmacol Sci 113: 263-266, 2010.

25. Shu Y, Sheardown SA, Brown C, Owen RP, Zhang S, Castro RA, Ianculescu AG, Yue L, Lo JC, Burchard EG, Brett CM and Giacomini KM: Effect of genetic variation in the organic cation transporter 1 (OCT1) on metformin action. J Clin Invest 117: 1422-1431, 2007.

26. Song IS, Shin HJ and Shin JG: Genetic variants of organic cation transporter 2 (OCT2) significantly reduce metformin uptake in oocytes. Xenobiotica 38: 1252-1262, 2008.

27. Cui R, Okada Y, Jang SG, Ku JL, Park JG, Kamatani Y, Hosono N, Tsunoda T, Kumar V, Tanikawa C, Kamatani N, Yamada R, Kubo M, Nakamura Y and Matsuda K: Common variant in 6q26-q27 is associated with distal colon cancer in an Asian population. Gut 60: 799-805, 2011.

28. Eeles RA, Kote-Jarai Z, Giles GG, Olama AA, Guy M, Jugurnauth SK, Mulholland S, LeongamornlertDA, Edwards SM, Morrison J, Field HI, Southey MC, Severi G, Donovan JL, Hamdy FC, Dearnaley DP, Muir KR, Smith C, Bagnato M, Ardern-Jones AT, Hall AL, O'Brien LT, Gehr-Swain BN, Wilkinson RA, Cox A, Lewis S, Brown PM, Jhavar SG, Tymrakiewicz M, Lophatananon A, Bryant SL; UK Genetic Prostate Cancer Study Collaborators; British Association of Urological Surgeons' Section of Oncology; UK ProtecT Study Collaborators, Horwich A, Huddart RA, Khoo VS, Parker CC, Woodhouse CJ, Thompson A, Christmas T, Ogden C, Fisher C, Jamieson C, Cooper CS, English DR, Hopper JL, Neal DE and Easton DF: Multiple newly identified loci associated with prostate cancer susceptibility. Nat Genet 40: 316-321, 2008. 